\title{
Title
}

\section{Allele frequency distribution of SNPs associated with levels of Vitamin D-binding protein and 25-hydroxyvitamin D}

\section{Authors}

Igor Nizamutdinov [1]

Yaroslav Popov [1]

Valery llinsky [1, 2, 3, 4]

Alexander Rakitko [1, 5]

1. Genotek Ltd.

2. Pirogov Russian National Research Medical University, Ostrovityanova str 1, 117997,Moscow, Russia

3. Institute of Biomedical Chemistry, Pogodinskaya street 10 build. 8, 119121, Moscow,Russia

4. Vavilov Institute of General Genetics, Gubkina str 3, 119333, Moscow, Russia

5. Lomonosov Moscow State University, Faculty of Mechanics and Mathematics, Leninskiye Gory, Main building, 119991, Moscow, Russia

Corresponding Authors

Igor Nizamutdinov

105120 Nastavnichesky lane 17 build.1, Moscow, Russia

Mobile: +79067353604

email: igor@genotek.ru

Alexandr Rakitko

105120 Nastavnichesky lane 17 build.1, Moscow, Russia

Mobile: +79104820017

email: rakitko@gmail.com 


\begin{abstract}
Haplotypes defined by rs7041/rs4588 in GC gene modulate 25-hydroxyvitamin D (25(OH)D) and vitamin D-binding protein (DBP) levels. To investigate the distributions of GC polymorphisms, the rs7041 and rs4588 allele and haplotypes frequencies were analyzed in samples from different Eurasian regions. The GC1S haplotype associated with high level of serum 25(OH)D had the maximum frequency in European populations (except Finish population). Such frequency distributions may be a result of adaptation to low solar insolation rate. Besides, there was a strong trend of increasing GC1F haplotype frequency from Europe $(10-15 \%)$ to Siberia and Easter Asia (40-45\%).
\end{abstract}

\title{
INTRODUCTION
}

Vitamin D deficiency is associated with negative health outcomes including cardiovascular disease (Skaaby, Thuesen, and Linneberg 2017), skeletal disorders (Wacker and Holick 2013) and type 2 diabetes mellitus (Harinarayan n.d.). After its synthesis in skin or absorption from dietary sources, vitamin D converts to 25-hydroxyvitamin D (25(OH)D). Serum total $25(\mathrm{OH}) \mathrm{D}$ is composed of three main metabolites: vitamin D-binding protein (DBP) bound form (85-90\%), serum albumin bound form (10-15\%) and free, unbound form $(0.03 \%)$ (Bikle, Malmstroem, and Schwartz 2017) vitamin D status depends on the level of total 25(OH)D that is used to define vitamin D sufficiency.

DBP encoded by GC gene inhibits some actions of vitamin D, because the bound fraction may be unavailable to act on target cells (Safadi FF n.d.). Twin studies established that mature serum DBP concentration has a significant heritable component (62\%) (Hunter D n.d.). Genetic variation in GC gene are shown to be associated with 25(OH)D levels (Wang et al. 2010). Recently, the racial difference was shown in DBP levels. Lower levels of DBP were shown in blacks compared to whites, although both groups had similar concentrations of estimated bioavailable 25(OH)D (Yousefzadeh, Shapses, and Wang 2014). However, the latest studies contradicted this racial difference and explained it by methodological faults (Nielson et al. 2016). It is still unclear whether DBP concentration relates to 25(OH)D level. Previous studies found no correlation between DBP and 25(OH)D levels (Bouillon R n.d.)(Winters SJ n.d.)(Blanton et al. 2011). The latest study revealed that high DBP level leads to low 25(OH)D level (Oleröd et al. 2017).

Two SNPs, rs7041 and rs4588, in GC gene form three haplotypes, namely GC1F, GC1S, and GC2, where GC1F = rs7041(A) and rs4588(G), GC1S = rs7041(C) and rs4588(G)

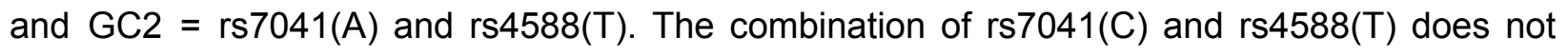
exist in humans. The haplotypes were shown to have additive effects on DBP concentrations (Powe et al. 2013) and presumably on affinities between DBP and 25(OH)D (Arnaud and Constans 1993)(Chun et al. 2014). However, contrary results have been published that describe no association between SNPs and affinities between DBP and 25(OH)D (Boutin, Galbraith, and Arnaud 1989; R. Bouillon et al. 1984).

Blacks and Asians are more likely to carry GC1F haplotype, which is associated with low DBP levels and has the highest affinity for $25(\mathrm{OH}) \mathrm{D}$. Whites are more likely to carry GC1S 
haplotype. The GC2 haplotype, which is associated with lower DBP levels and has a lower affinity for $25(\mathrm{OH}) \mathrm{D}$, is frequently found in whites and rarely found in blacks (Chun RF n.d.; Powe CE n.d.).

Previous study found no differences in 25(OH)D values for children and adolescents, adults and elderly (Hilger et al. 2014), except for Asia/Pacific region where low 25(OH)D values found for Chinese children and adolescents. Also there were no significant sex-related differences in 25(OH)D before examining the data by region. Taking into account these data, we suggest that geographical region and GC polymorphisms are the main factors of population total 25(OH)D level difference.

We conducted a study to determine vitamin D-binding protein genotypes and haplotypes associated with vitamin $\mathrm{D}$ level in different populations.

\section{MATERIALS AND METHODS}

\section{Data collection}

The global rs7041 and rs4588 allele frequencies were drawn using GnomAD database (Lek et al. 2016). The rs7041 allele frequencies in different ethnic group were obtained from Alfred database (Rajeevan et al. 2012).

To investigate population differences in SNP frequencies in Eurasian populations, the genome data of Genotek Ltd. customers were analyzed. Totally, 4118 samples were studied with an average age of $33.3 \pm 15.7$. The group includes $46 \%$ female samples. All ethical requirements were covered by providing with informed consent of participants. Data used in our analysis were collected prior to February, 2018.

\section{Genotyping}

Genotek Ltd. samples were drawn from the DNA biobank of Genotek Ltd., a direct-to-consumer genetics company. All samples were genotyped using customized Illumina InfiniumCoreExome 24 v1.1 beadchip with 550,000 standard plus 12,000 add-on SNPs and Illumina Global Screening Array v.1 and v.2.

\section{Statistical analysis}

Imputing and phasing. Haplotypes were derived based on phasing using Beagle 5 ("Beagle 5.0" n.d.) with HRC panel ("The Haplotype Reference Consortium" n.d.) as the reference. Beagle 5 also was used for rs4588 imputation due to its absence on Illumina Global Screening Array.

Population inference. Ancestry was predicted using ADMIXTURE Version 1.3.0 in predictive mode (Alexander, Novembre, and Lange 2009). The samples from Behar et al. study (Behar et al. 2013) was used as original populations after exclusion of non-Ashkenazi jews. Each sample was assigned a population with maximal percent, but only if it was more than $50 \%$. 


\section{RESULTS}

The global rs7041 and rs4588 allele frequencies are present in Table 1. The rs4588 (T) allele associated with increased levels of vitamin D-binding protein and decreased levels of total $25(\mathrm{OH}) \mathrm{D}$ in whites had the lowest frequency in African population. In whites, the lowest frequencies were observed in Finnish and Latino populations. The highest frequencies were shown for South Asian and Ashkenazi Jewish.

In contrast, rs7041 (A) allele associated with lower DBP levels and decreased levels of total 25(OH)D among blacks had the highest frequencies in Africans. In whites, the highest frequency was observed in Finnish population. Thus in African and Finnish populations, there were the highest frequencies of alleles associated with low DBP level.

Table 1

Global rs4588 and rs7041 allele frequencies

\begin{tabular}{|c|c|c|c|c|}
\hline \multirow{2}{*}{$\begin{array}{l}\text { Geographic } \\
\text { region }\end{array}$} & \multicolumn{2}{|c|}{ Sample size (n) } & \multirow{2}{*}{$\begin{array}{c}\begin{array}{c}\text { Allele } \\
\text { Frequencies }\end{array} \\
\text { rs4588-T }\end{array}$} & \multirow{2}{*}{$\begin{array}{c}\begin{array}{c}\text { Allele } \\
\text { Frequencies }\end{array} \\
\text { rs7041-A }\end{array}$} \\
\hline & rs4588 (G/T) & rs7041 (A/C) & & \\
\hline $\begin{array}{l}\text { European } \\
\text { (non-Finnish) }\end{array}$ & 64540 & 64539 & 0.282 & 0.429 \\
\hline $\begin{array}{l}\text { European } \\
\text { (Finnish) }\end{array}$ & 12556 & 9964 & 0.201 & 0.713 \\
\hline $\begin{array}{l}\text { Ashkenazi } \\
\text { Jewish }\end{array}$ & 5185 & 5185 & 0.286 & 0.403 \\
\hline East Asian & 9970 & 3607 & 0.271 & 0.446 \\
\hline South Asian & 15287 & 12557 & 0.298 & 0.326 \\
\hline Latino & 17663 & 17662 & 0.208 & 0.492 \\
\hline African & 12474 & 12475 & 0.099 & 0.842 \\
\hline Other & 3609 & 15292 & 0.262 & 0.449 \\
\hline Total & 141284 & 141281 & 0.25 & 0.486 \\
\hline
\end{tabular}

To investigate allele frequency diversity within large geographical regions, the rs7041 allele frequencies were compared between different populations (Figure 1). 
Thereafter, the mean $25(\mathrm{OH}) \mathrm{D}$ level was obtained in various genotypes for different population (STable 1).

The allele and haplotype frequencies of rs7041 and rs4588 were estimated in a sample of 4118 Genotek Ltd customers. The obtained haplotype frequencies are present in Table 2. A maximum frequency was shown for haplotype GC1S associated with high level of serum 25(OH)D. The lowest frequency was observed for GC1F associated with lower level of serum 25(OH)D comparing with GC1S haplotype.

Table 2. Haplotype frequencies in Genotek biobank samples.

\begin{tabular}{|c|c|c|}
\hline Haplotype & Alleles & Frequency, $\%$ \\
\hline GC1S & rs7041(C)-rs4588(G) & 56.4 \\
\hline GC2 & rs7041(A)-rs4588(T) & 29.9 \\
\hline GC1F & rs7041(A)-rs4588(G) & 13.7 \\
\hline & rs7041(C)-rs4588(T) & 0 \\
\hline
\end{tabular}

To investigate haplotypes distribution in Genotek Ltd samples divided in different populations, population origins were defined for 4118 DNA samples of Genotek Ltd biobank. Major part of samples had East Europe origin. Totally, nine clusters were defined in the sample set. The rs4588(T) and rs7041(A) allele frequencies are present on SFigure 1 and SFigure 2, respectively.

The haplotype GC1F has low frequencies in all populations, except East Asian and Siberia (SFigure 3). Haplotype frequencies for GC1S are present on Figure 2. GC1S haplotype was the most frequent in all populations except East Asians and Siberia, where this haplotype had the lowest frequencies. Also there was a slight trend of increasing haplotype frequency from north to south.

The highest GC2 frequency was shown for East Europe population. There were two trends of decreasing haplotype frequency, although the gradient was lower comparing with those of GC1F and GC1S. The GC2 frequency was lower for east populations (Siberia and East Asia). The second consists of decreasing haplotype frequency from north to south. There also was a difference in frequencies between Caucasus populations. North Caucasus population had a higher GC2 frequency comparing to South Caucasus population. Jewish population had the lowest GC2 frequency. 
bioRxiv preprint doi: https://doi.org/10.1101/564229; this version posted February 28, 2019. The copyright holder for this preprint (which was not certified by peer review) is the author/funder, who has granted bioRxiv a license to display the preprint in perpetuity. It is made available under aCC-BY 4.0 International license.

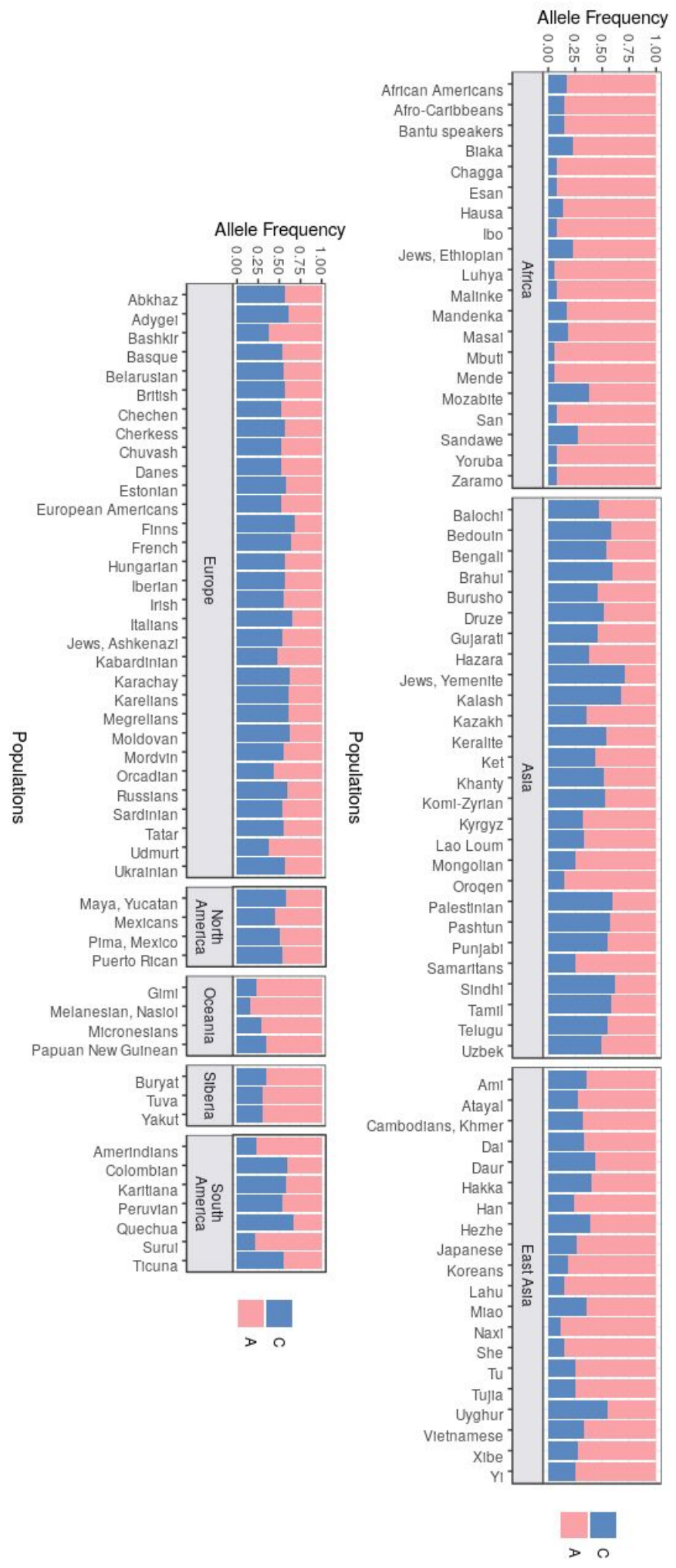

Figure 1. The rs7041 allele frequencies in different populations 
bioRxiv preprint doi: https://doi.org/10.1101/564229; this version posted February 28, 2019. The copyright holder for this preprint (which was not certified by peer review) is the author/funder, who has granted bioRxiv a license to display the preprint in perpetuity. It is made available under aCC-BY 4.0 International license.

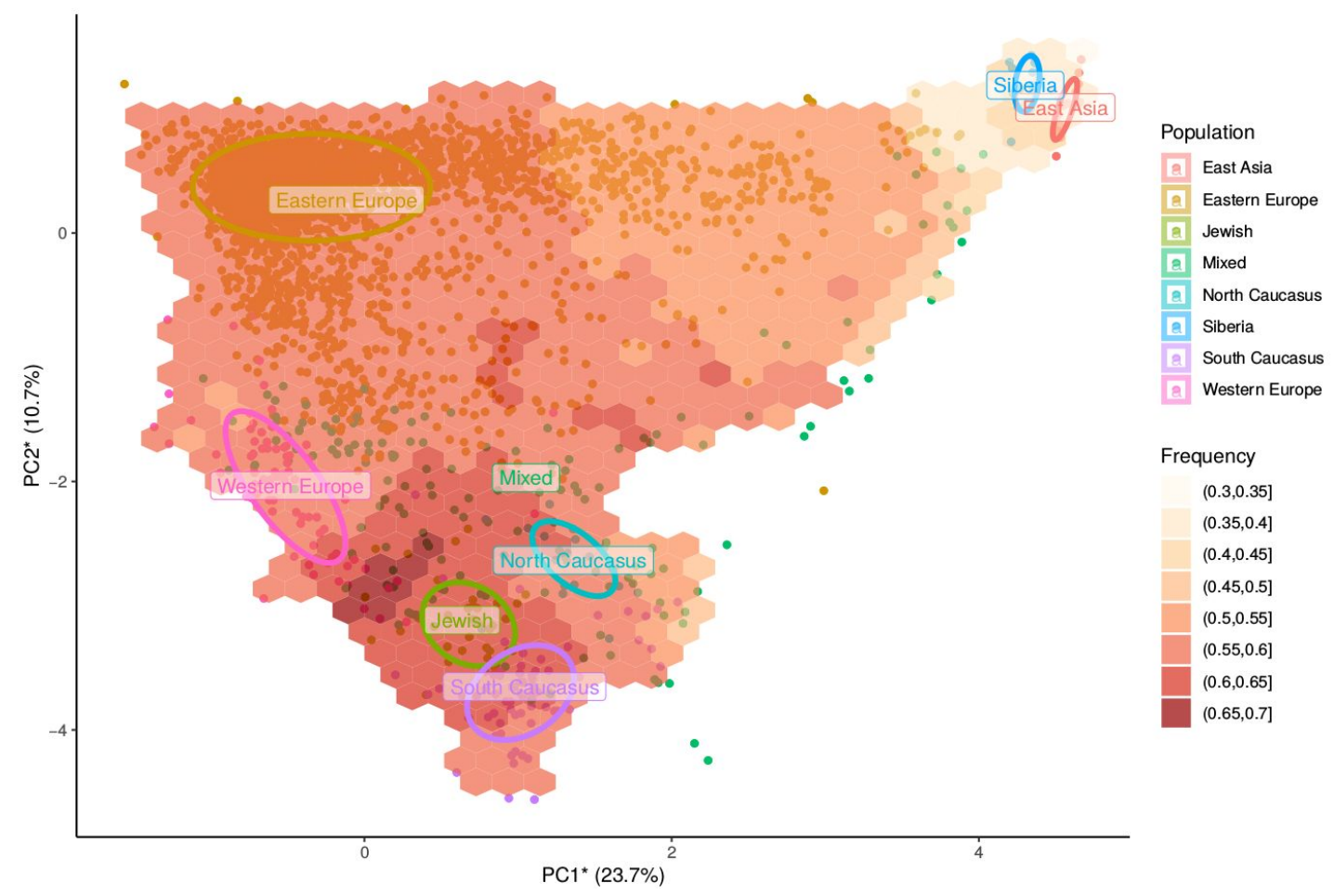

Figure 2. The GC1S haplotype frequencies in different Eurasian populations.

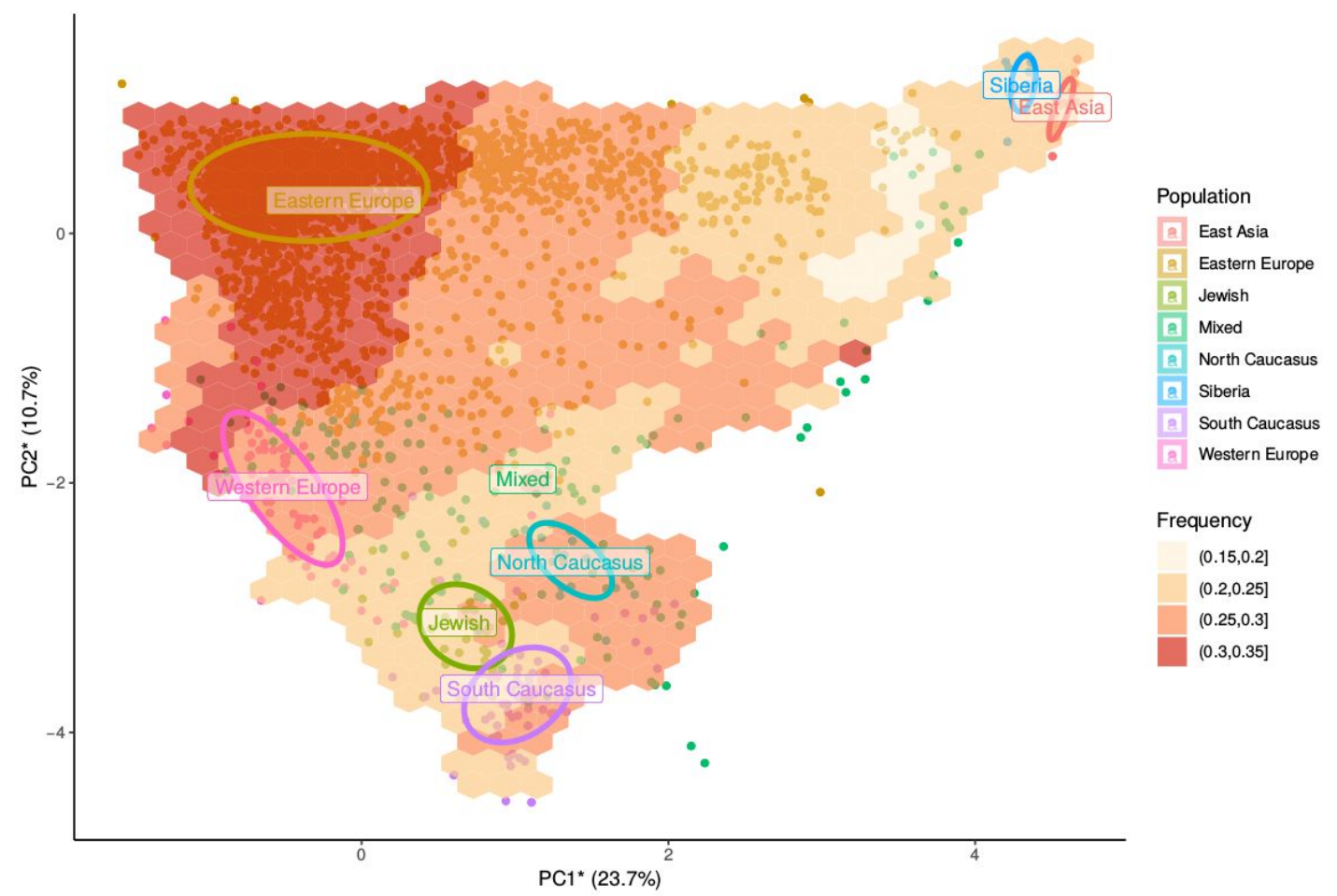

Figure 3. The GC2 haplotype frequencies in different Eurasian populations. 


\section{DISCUSSION}

Globally, there were maximum rs7041(A) allele frequency in African region. The Finnish population ranked second in rs7041(A) allele frequency. Recently, it was shown that blacks had the higher total 25(OH)D level comparing whites and Asians. At the same time, Finnish population had lower total 25(OH)D level comparing with most other European populations (Hilger et al. 2014). In Finns, the high frequency of rs7041(A) allele may be the consequences of a population bottlenecks resulting from consecutive founder effects (Chheda et al. 2017). In spite of rs7041 association with total 25(OH)D level in blacks, we suggest that genetic factors have minor influence on total $25(\mathrm{OH}) \mathrm{D}$ level in blacks.

Previous reviews (van Schoor and Lips 2011)(Lips 2007) reported a north-south gradient for 25(OH)D level in Europe, with Scandinavian countries showing generally higher values than European and Southern countries. We found no critical differences in rs7041(A) allele frequency in European populations except Finnish population. Probable these gradient is explained by non-genetic factors such as differences in skin pigmentation, diets rich in oily fish and low-fat milk, the common use of cod-liver oil and a higher degree of vitamin D supplementation in Scandinavian countries (Hagenau et al. 2009).

The GC1F haplotype had the lowest frequency in Genotek Ltd samples. However it was the most frequent in East Asia and Siberia population. Previously, it was shown that GC1F haplotype is the ancestral form of the gene (Advances in Forensic Haemogenetics 1994). This haplotype probably leads to the highest DBP affinity and lowest bioavailable 25(OH)D comparing with other haplotypes, what seems to be profitable in regions with high solar insolation rate. 25(OH)D bound form is inactive and perhaps could be a kind of storage of 25(OH)D overload (R. Bouillon and Van Baelen 1980).

The GC1S haplotype had the highest frequency in Genotek Ltd samples, except samples of East Asian and Siberia origin. Our results correspond to previous studies demonstrating dependence of GC1S frequency on the distance from the equator (Roger Bouillon 2017). GC1S variant occured at highest frequency at high latitudes. Vitamin D amount synthesized in skin is lower at high latitudes due to lower solar insolation rate. This haplotype is associated with lower DBP affinity comparing with GC1F and the highest levels of both total and bioavailable 25(OH)D comparing with other haplotypes (Yao et al. 2017), what seems to be adaptive factor to low vitamin D synthesis rate. Solar insolation rate is higher in Siberia and East Asia comparing with Europe, what seems to be a possible explanation of especial low GC1S level in these populations.

The frequency of GC2 haplotype was $29.9 \%$ in Genotek Ltd samples. The GC2 frequency variance was lower for different populations. This haplotype is associated with lowest DBP affinity comparing with other haplotypes and higher level of bioavailable 25(OH)D comparing with GC1F (Yao et al. 2017; Braithwaite et al. 2015), what could benefit in case of lower solar insolation rate.

Our study has several limitations. Not all populations living in Russia has been included in study. It is possible that small populations have different haplotype frequencies than large population groups. Research participants were drawn from customers of genetic company, what potentially could influence on sampling representativeness. 


\section{References}

Advances in Forensic Haemogenetics. 1994.

Alexander, David H., John Novembre, and Kenneth Lange. 2009. "Fast Model-Based Estimation of Ancestry in Unrelated Individuals." Genome Research 19 (9): 1655-64.

Arnaud, J., and J. Constans. 1993. "Affinity Differences for Vitamin D Metabolites Associated with the Genetic Isoforms of the Human Serum Carrier Protein (DBP)." Human Genetics 92 (2): 183-88.

"Beagle 5.0." n.d. Accessed February 25, 2019. https://faculty.washington.edu/browning/beagle/beagle.html.

Behar, Doron M., Mait Metspalu, Yael Baran, Naama M. Kopelman, Bayazit Yunusbayev, Ariella Gladstein, Shay Tzur, et al. 2013. "No Evidence from Genome-Wide Data of a Khazar Origin for the Ashkenazi Jews." Human Biology 85 (6): 859-900.

Bikle, Daniel D., Sofie Malmstroem, and Janice Schwartz. 2017. "Current Controversies: Are Free Vitamin Metabolite Levels a More Accurate Assessment of Vitamin D Status than Total Levels?" Endocrinology and Metabolism Clinics of North America 46 (4): 901-18.

Blanton, Dustin, Zhao Han, Lindsey Bierschenk, M. V. Prasad Linga-Reddy, Hongjie Wang, Michael Clare-Salzler, Michael Haller, et al. 2011. "Reduced Serum Vitamin D-Binding Protein Levels Are Associated With Type 1 Diabetes." Diabetes 60 (10): 2566.

Bouillon R, Et al. n.d. "The Measurement of the Vitamin D-Binding Protein in Human Serum. PubMed - NCBI." Accessed February 27, 2019.

https://www.ncbi.nlm.nih.gov/pubmed/885987.

Bouillon, Roger. 2017. "Genetic and Racial Differences in the Vitamin D Endocrine System." Endocrinology and Metabolism Clinics of North America 46 (4): 1119-35.

Bouillon, R., and H. Van Baelen. 1980. "THE TRANSPORT OF VITAMIN D." Pediatric Research 14 (2): 164.

Bouillon, R., E. Van Herck, I. Jans, B. K. Tan, H. Van Baelen, and P. De Moor. 1984. "Two Direct (nonchromatographic) Assays for 25-Hydroxyvitamin D." Clinical Chemistry 30 (11): 1731-36.

Boutin, B., R. M. Galbraith, and P. Arnaud. 1989. "Comparative Affinity of the Major Genetic Variants of Human Group-Specific Component (vitamin D-Binding Protein) for 25-(OH) Vitamin D." Journal of Steroid Biochemistry 32 (1A): 59-63.

Braithwaite, V. S., K. S. Jones, I. Schoenmakers, M. Silver, A. Prentice, and B. J. Hennig. 2015. "Vitamin D Binding Protein Genotype Is Associated with Plasma 25OHD Concentration in West African Children." Bone 74 (May): 166-70.

Chheda, Himanshu, Priit Palta, Matti Pirinen, Shane McCarthy, Klaudia Walter, Seppo Koskinen, Veikko Salomaa, et al. 2017. "Whole-Genome View of the Consequences of a Population Bottleneck Using 2926 Genome Sequences from Finland and United Kingdom." European Journal of Human Genetics: EJHG 25 (4): 477-84.

Chun, Rene F., Bradford E. Peercy, Eric S. Orwoll, Carrie M. Nielson, John S. Adams, and Martin Hewison. 2014. "Vitamin D and DBP: The Free Hormone Hypothesis Revisited." The Journal of Steroid Biochemistry and Molecular Biology 144 Pt A (October): 132-37.

Chun RF, Et al. n.d. "Vitamin D and DBP: The Free Hormone Hypothesis Revisited. - PubMed NCBI." Accessed February 20, 2019. https://www.ncbi.nlm.nih.gov/pubmed/24095930/.

Fang, Yue, Joyce B. J. van Meurs, Pascal Arp, Johannes P. T. van Leeuwen, Albert Hofman, Huibert A. P. Pols, and André G. Uitterlinden. 2009. "Vitamin D Binding Protein Genotype and Osteoporosis." Calcified Tissue International 85 (2): 85-93.

Hagenau, T., R. Vest, T. N. Gissel, C. S. Poulsen, M. Erlandsen, L. Mosekilde, and P. 
Vestergaard. 2009. "Global Vitamin D Levels in Relation to Age, Gender, Skin Pigmentation and Latitude: An Ecologic Meta-Regression Analysis." Osteoporosis International: A Journal Established as Result of Cooperation between the European Foundation for Osteoporosis and the National Osteoporosis Foundation of the USA 20 (1): 133-40.

Harinarayan, C. V. n.d. "Vitamin D and Diabetes Mellitus. - PubMed - NCBI." Accessed February 20, 2019. https://www.ncbi.nlm.nih.gov/pubmed/24776618.

Hilger, Jennifer, Angelika Friedel, Raphael Herr, Tamara Rausch, Franz Roos, Denys A. Wahl, Dominique D. Pierroz, Peter Weber, and Kristina Hoffmann. 2014. "A Systematic Review of Vitamin D Status in Populations Worldwide." The British Journal of Nutrition 111 (1): 23-45.

Hunter D, Et al. n.d. "Genetic Contribution to Bone Metabolism, Calcium Excretion, and Vitamin D and Parathyroid Hormone Regulation. - PubMed - NCBI." Accessed February 25, 2019. https://www.ncbi.nlm.nih.gov/pubmed/11204437/.

Janssens, Wim, Roger Bouillon, Bart Claes, Claudia Carremans, An Lehouck, lan Buysschaert, Johan Coolen, Chantal Mathieu, Marc Decramer, and Diether Lambrechts. 2010. "Vitamin

D Deficiency Is Highly Prevalent in COPD and Correlates with Variants in the Vitamin D-Binding Gene." Thorax 65 (3): 215-20.

Jorde, Rolf, Henrik Schirmer, Tom Wilsgaard, Ellisiv Bøgeberg Mathiesen, Inger Njølstad, Maja-Lisa Løchen, Ragnar Martin Joakimsen, and Guri Grimnes. 2015. "The DBP Phenotype Gc-1f/Gc-1f Is Associated with Reduced Risk of Cancer. The Troms $\varnothing$ Study." PloS One 10 (5): e0126359.

Lafi, Zainab M., Yacoub M. Irshaid, Mohammed El-Khateeb, Kamel M. Ajlouni, and Dana Hyassat. 2015. "Association of rs7041 and rs4588 Polymorphisms of the Vitamin D Binding Protein and the rs10741657 Polymorphism of CYP2R1 with Vitamin D Status Among Jordanian Patients." Genetic Testing and Molecular Biomarkers 19 (11): 629-36.

Lek, Monkol, Konrad J. Karczewski, Eric V. Minikel, Kaitlin E. Samocha, Eric Banks, Timothy Fennell, Anne H. O'Donnell-Luria, et al. 2016. "Analysis of Protein-Coding Genetic Variation in 60,706 Humans." Nature 536 (7616): 285-91.

Lips, P. 2007. "Vitamin D Status and Nutrition in Europe and Asia." The Journal of Steroid Biochemistry and Molecular Biology 103 (3-5): 620-25.

Nielson, Carrie M., Kerry S. Jones, Rene F. Chun, Jon M. Jacobs, Ying Wang, Martin Hewison, John S. Adams, et al. 2016. "Free 25-Hydroxyvitamin D: Impact of Vitamin D Binding Protein Assays on Racial-Genotypic Associations." The Journal of Clinical Endocrinology and Metabolism 101 (5): 2226-34.

Oleröd, Göran, Lillemor Mattsson Hultén, Ola Hammarsten, and Eva Klingberg. 2017. "The Variation in Free 25-Hydroxy Vitamin D and Vitamin D-Binding Protein with Season and Vitamin D Status." Endocrine Connections 6 (2): 111.

Pekkinen, Minna, Elisa Saarnio, Heli T. Viljakainen, Elina Kokkonen, Jette Jakobsen, Kevin Cashman, Outi Mäkitie, and Christel Lamberg-Allardt. 2014. "Vitamin D Binding Protein Genotype Is Associated with Serum 25-Hydroxyvitamin D and PTH Concentrations, as Well as Bone Health in Children and Adolescents in Finland." PloS One 9 (1): e87292.

Powe, Camille E., Michele K. Evans, Julia Wenger, Alan B. Zonderman, Anders H. Berg, Michael Nalls, Hector Tamez, et al. 2013. "Vitamin D-Binding Protein and Vitamin D Status of Black Americans and White Americans." The New England Journal of Medicine 369 (21): 1991.

Powe CE, Et al. n.d. "Vitamin D-Binding Protein and Vitamin D Status of Black Americans and White Americans. - PubMed - NCBI." Accessed February 20, 2019. https://www.ncbi.nlm.nih.gov/pubmed/24256378.

Rajeevan, Haseena, Usha Soundararajan, Judith R. Kidd, Andrew J. Pakstis, and Kenneth K. 
Kidd. 2012. "ALFRED: An Allele Frequency Resource for Research and Teaching." Nucleic Acids Research 40 (Database issue): D1010-15.

Safadi FF, Et al. n.d. "Osteopathy and Resistance to Vitamin D Toxicity in Mice Null for Vitamin

D Binding Protein. - PubMed - NCBI." Accessed February 20, 2019.

https://www.ncbi.nlm.nih.gov/pubmed/9916136/.

Schoor, Natasja M. van, and Paul Lips. 2011. "Worldwide Vitamin D Status." Best Practice \&

Research. Clinical Endocrinology \& Metabolism 25 (4): 671-80.

Sinotte, Marc, Caroline Diorio, Sylvie Bérubé, Michael Pollak, and Jacques Brisson. 2009.

"Genetic Polymorphisms of the Vitamin D Binding Protein and Plasma Concentrations of 25-Hydroxyvitamin D in Premenopausal Women." The American Journal of Clinical Nutrition 89 (2): 634-40.

Skaaby, Tea, Betina H. Thuesen, and Allan Linneberg. 2017. "Vitamin D, Cardiovascular

Disease and Risk Factors." Advances in Experimental Medicine and Biology 996: 221-30.

"The Haplotype Reference Consortium." n.d. Accessed February 28, 2019.

http://www.haplotype-reference-consortium.org/.

Wacker, Matthias, and Michael F. Holick. 2013. "Vitamin D - Effects on Skeletal and

Extraskeletal Health and the Need for Supplementation." Nutrients 5 (1): 111-48.

Wang, Thomas J., Feng Zhang, J. Brent Richards, Bryan Kestenbaum, Joyce B. van Meurs, Diane Berry, Douglas P. Kiel, et al. 2010. "Common Genetic Determinants of Vitamin D Insufficiency: A Genome-Wide Association Study." The Lancet 376 (9736): 180-88.

Winters SJ, Et al. n.d. "Influence of Obesity on Vitamin D-Binding Protein and 25-Hydroxy Vitamin D Levels in African American and White Women. - PubMed - NCBI." Accessed February 27, 2019. https://www.ncbi.nlm.nih.gov/pubmed/19303961.

Yao, Pang, Liang Sun, Ling Lu, Hong Ding, Xiafei Chen, Lixin Tang, Xinming Xu, et al. 2017. "Effects of Genetic and Nongenetic Factors on Total and Bioavailable 25(OH)D Responses to Vitamin D Supplementation." The Journal of Clinical Endocrinology and Metabolism 102 (1): 100-110.

Yousefzadeh, Pegah, Sue A. Shapses, and Xiangbing Wang. 2014. "Vitamin D Binding Protein Impact on 25-Hydroxyvitamin D Levels under Different Physiologic and Pathologic Conditions." International Journal of Endocrinology 2014. https://doi.org/10.1155/2014/981581.

Zhang, Zeng, Jin-Wei He, Wen-Zhen Fu, Chang-Qing Zhang, and Zhen-Lin Zhang. 2013. "An Analysis of the Association between the Vitamin D Pathway and Serum 25-Hydroxyvitamin D Levels in a Healthy Chinese Population." Journal of Bone and Mineral Research: The Official Journal of the American Society for Bone and Mineral Research 28 (8): 1784-92. 


\section{Supplementary}

Table 1. Mean 25(OH)Vitamin D Level (nmol/L) in the Various Genotypes obtained in different populations.

\begin{tabular}{|l|l|l|l|l|l|}
\hline Population & $\begin{array}{l}\text { Number of } \\
\text { patients }\end{array}$ & Sex & $\begin{array}{l}\text { GC } \\
\text { 1s/1s }\end{array}$ & $\begin{array}{l}\text { GC } \\
1 f / 1 f\end{array}$ & $\begin{array}{l}\text { GC } \\
2 / 2\end{array}$ \\
\hline Norway (Jorde et al. 2015) & 11704 & both & 55.4 & 52.2 & 46.9 \\
\hline Denmark (Fang et al. 2009) & 538 & both & 65.8 & 58.5 & 64.9 \\
\hline French (Sinotte et al. 2009) & 727 & female & 67.5 & -- & 58.4 \\
\hline Belgian (Janssens et al. 2010) & 150 & both & 65.75 & -- & 51.5 \\
\hline Chineese (Zhang et al. 2013) & 2897 & both & 50.75 & -- & 42.25 \\
\hline Finland (Pekkinen et al. 2014) & 160 & girls & -- & -- & 38.5 \\
\hline Finland (Pekkinen et al. 2014) & 73 & boys & -- & -- & 45.3 \\
\hline Jordanian (Lafi et al. 2015) & 200 & both & 90.25 & -- & 31 \\
\hline Mean & & & $\mathbf{6 5 . 9}$ & $\mathbf{5 5 . 3 5}$ & $\mathbf{4 7 . 3}$ \\
\hline
\end{tabular}




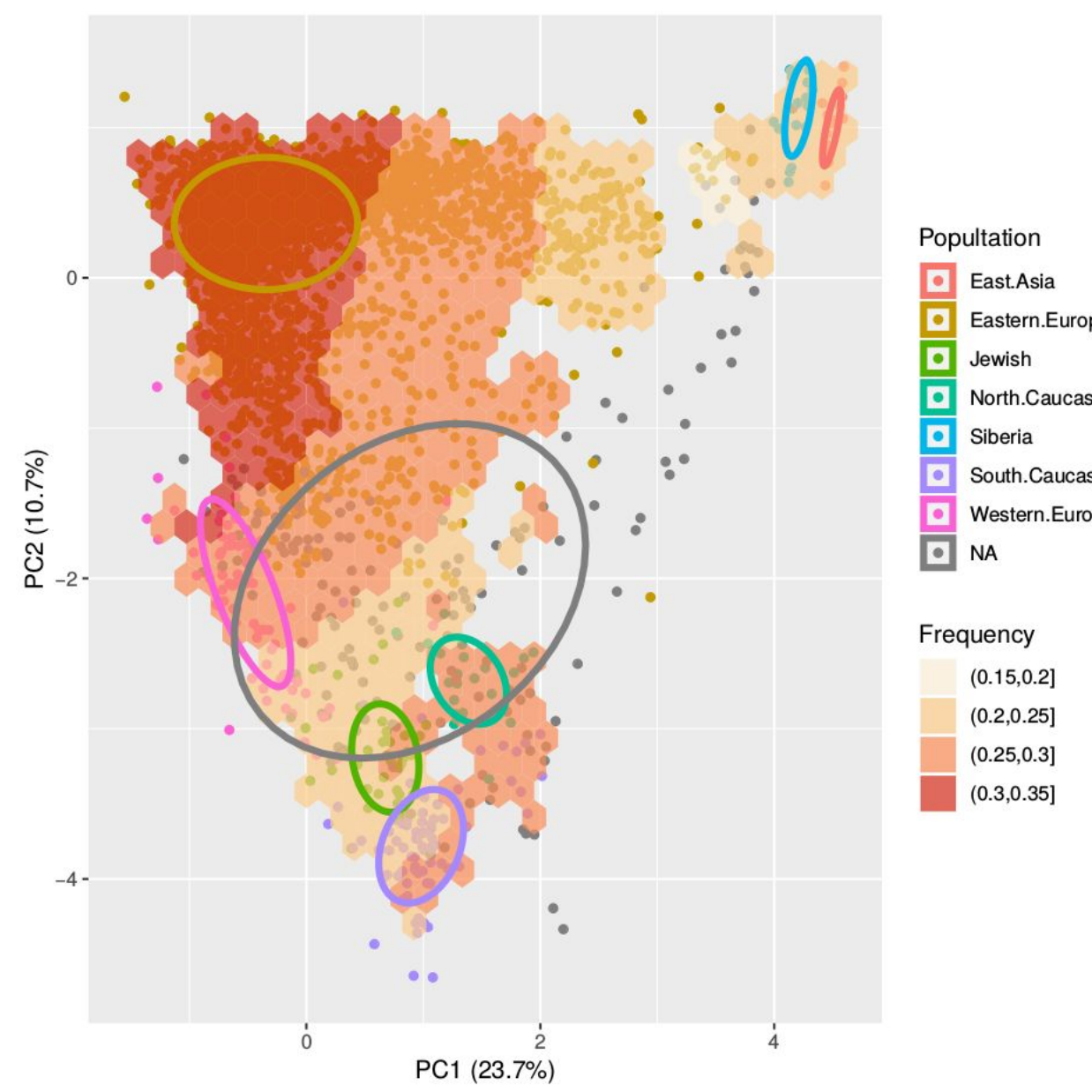

Figure 1. The rs4588(T) allele frequencies in different Eurasian populations. There were trends of decreasing allele frequency from west to east and from north to south. The highest T-allele frequency was observed in samples with east Europe origin. Lower T-allele frequency was shown for East Asia and Siberia populations. There was some difference of frequencies between Caucasus populations. North Caucasus population had a higher T-allele frequency comparing to South Caucasus population. Jewish population had low T-allele frequency. 


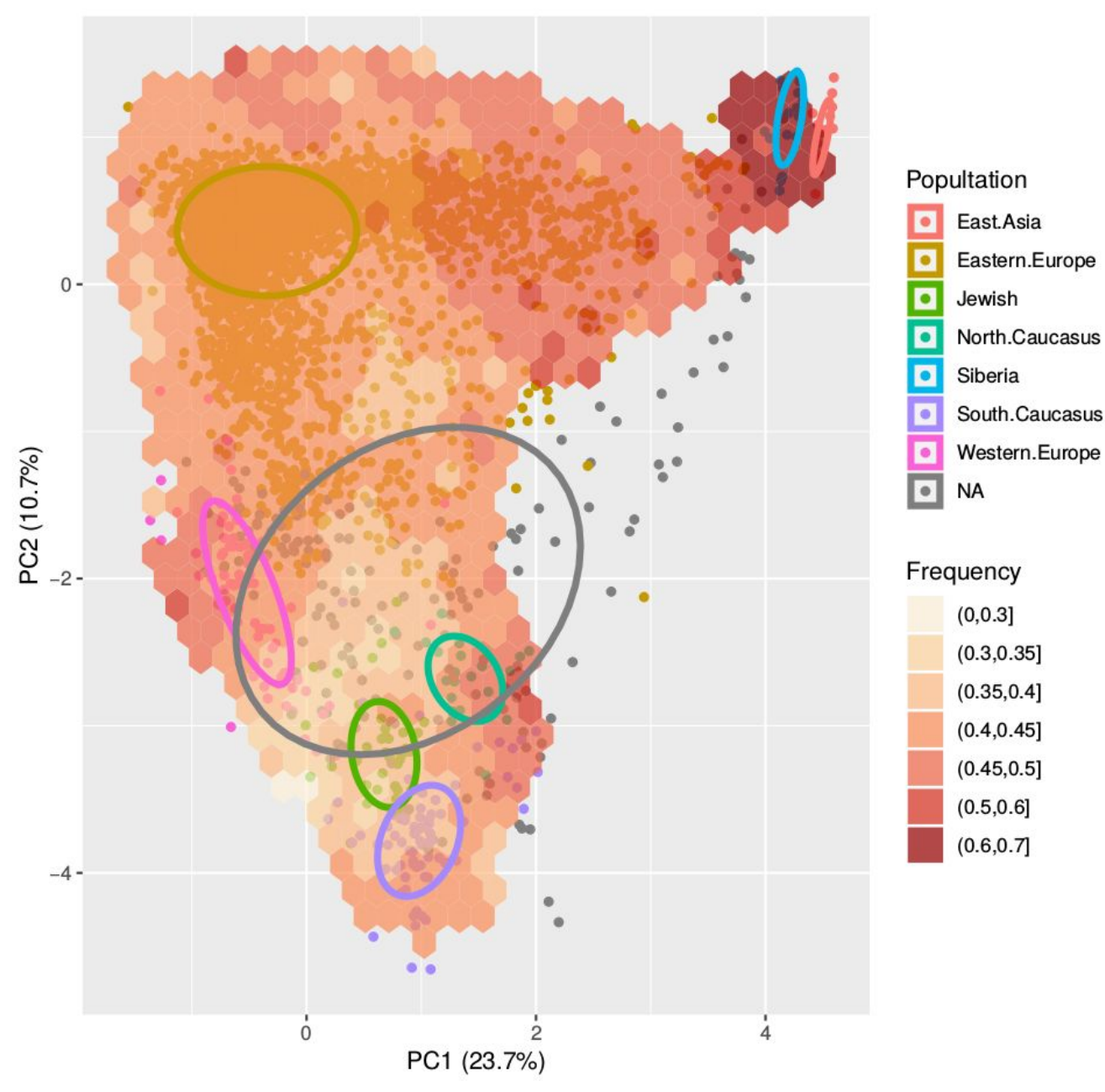

Figure 2. The rs7041(A) allele frequencies in different Eurasian populations. There was a trend of decreasing A-allele frequency from east to west and from north to south. Siberian and East Asian populations had the highest A-allele frequencies. There also was a difference of frequencies between Caucasus populations. North Caucasus population had a higher T-allele frequency comparing to South Caucasus population. Jewish population had the lowest T-allele frequency. 


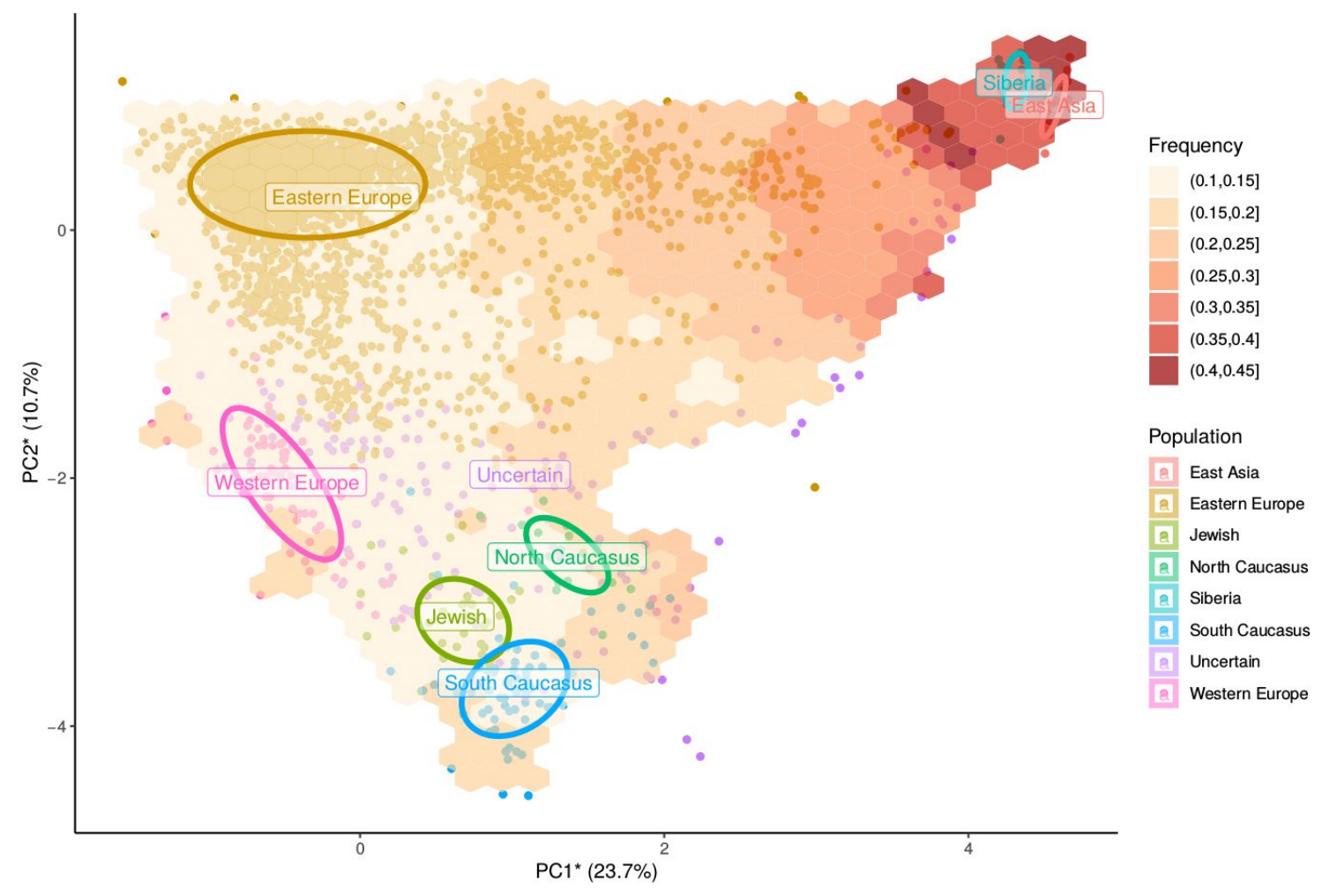

Figure 3. The GC1F haplotype frequencies in different Eurasian populations. European, Caucasus and Jewish populations had similar low frequencies. Siberian and East Asian populations had the highest A-allele frequencies. 